\title{
¿ESTÁ EN PELIGRO EL PERIODISMO?
}

José Rodríguez Elizondo ${ }^{1}$

\section{HISTORIA DEL TEMA}

Debatir sobre este tema tiene una historia propia. En un artículo publicado el año $2000^{2}$ me referí al futuro de la prensa, las nuevas tecnologías de la comunicación y la hiper y auto-información como eventuales amenazas. El tema, de apariencia imponente y con hipótesis ominosas, tuvo de mi parte una decodificación optimista. Dado que aquel futuro lleva ya más de una década de desarrollo, este nuevo artículo servirá para contrastar las percepciones y los pronósticos de entonces. Lo haré en el disfrute de la mayor libertad crítica que es posible concebir, que es la que se expresa como autocrítica.

Si pudiera hacer una síntesis del artículo de 2000 diría que: a) tomé como referente la prensa-papel y la televisión de España y América Latina; b) el contexto político fue el de la Guerra Fría y la transición democrática; c) el contexto tecnológico tenía como soportes la CNN y el inicio de la expansión de Internet; d) la tesis principal era la correlación entre las democracias desarrolladas y la prensa modélica y/o tradicional; e) había una primera tesis subordinada, según la cual la calidad de la democracia estaba vinculada a la calidad de la prensa modélica; y f) según una segunda tesis subordinada, las nuevas tecnologías (NTs) debilitaban la participación social por el efecto que yo llamaba "autismo del internauta".

El artículo tenía el siguiente supuesto virtuoso: aunque la prensa aludida no era una institución de beneficencia, pues tenía fines de lucro,

\footnotetext{
1 Profesor de Relaciones Internacionales de la Facultad de Derecho de la Universidad de Chile y Director de Realidad y Perspectivas.

2 Rodríguez Elizondo, José, "El futuro de la prensa", en Revista Diplomacia $n^{\circ} 79$, julio-septiembre de 2000, Santiago, pp. 92-105.
} 
se configuraba como una empresa que cumplía un rol diferenciado, con códigos éticos propios, representando distintas sensibilidades en lo político-cultural y luciendo un sesgo crítico necesario. Esto último porque, como cualquier periodista sabe, un diario oficialista no es buen negocio. Con base en ese supuesto virtuoso se concluía que la prensa modélica de las democracias tenía una alta función socializadora. En su virtud afirmaba la unidad del Estado, al tiempo que exhibía su diversidad interna desde el mundo de los futbolistas al de los intelectuales (para usar una antinomia grata a José Ortega y Gasset). Simultáneamente se constituía en soporte del debate social en oficinas, talleres, calles y plazas, como jamás podría hacerlo una pantalla de PC. Desde tal perspectiva, la prensa modélica aparecía como un producto interactivo del Estado, abiertamente funcional a la paz, la cultura democrática y las libertades ciudadanas.

\section{AUTOCRÍTICA FEROZ}

Aquella fue, lo reconozco, una tesitura más romántica que realista, ya que contenía una excesiva idealización de la prensa que yo categorizaba como modélica. Repasándola, a la luz de lo sucedido en estos últimos diez años, creo que estuvo quíntuplemente sesgada.

El primer sesgo estuvo en la biografía del autor, esto es, en lo que podríamos llamar mi "circunstancia condicionante". Esta descansaba en un Chile donde viví entre la democracia, la dictadura y la transición democrática. Suponía un exilio en la República Democrática alemana, equivalente a un doctorado en socialismo real. También contenía varios años en la Organización de las Naciones Unidas, con una experiencia en vivo y en directo sobre las tensiones entre su burocracia y su utopía.

El segundo sesgo fue una especie de adhesión, por escarmiento, al realismo minimalista democrático. Con tácita ironía churchilliana levanté el binomio "democracia-prensa modélica" como equivalente al peor sistema político-informativo, con excepción de todos los demás. 
Esto reflejaba el posibilismo de la época, que aconsejaba asumir lo bueno contra lo mejor, pues lo mejor podía ser sólo un nuevo disfraz de las "ideologías totales". El escarmiento de base consistía en que la democracia realmente existente pudo parecer mediocre pero, contrastada con el socialismo realmente existente, era mucho más que una simple forma. En todo caso, una forma preferible a las utopías de patria o muerte.

El tercer sesgo consistió en la proyección de la utopía compleja de la onu tras el fin de la Guerra Fría, específicamente, por aquellos "dividendos de la paz" que levantó el Secretario General peruano de la época, Javier Pérez de Cuéllar. En mi análisis, estos contenían la plenitud del binomio "democracia-prensa modélica", pues el nuevo orden internacional en plasmación permitiría un desarrollo pleno de ambos factores. El profeta más conocido de esta tendencia hiperoptimista fue Francis Fukuyama y la plasmó en su tesis sobre el fin de la Historia.

El cuarto sesgo yacía camuflado bajo la inercia de las estructuras binarias de la Guerra Fría. Aquí estaba la estructura geopolítica "este contra oeste", en evolución hacia bipolaridades sustitutas como "mundo cristiano versus mundo islámico" o "consumidores versus productores de petróleo". El profeta respectivo fue Samuel Huntington y su tesis de "la guerra de civilizaciones", que concluía con una supratesis descarnada: "West, against the rest" y, más sintéticamente, "USA against the rest".

El quinto sesgo era la falta de dimensionamiento de las NTs. En el año 2000 hablábamos de nuevas tecnologías de la información, en el marco de la utopía onusiana sobre un "nuevo orden mundial informativo". No sabíamos que eran NTs a secas, y que no se reducían a lo informativo, aunque lo comprendieran. Puesto en nomenclatura que hoy nos es familiar, ignorábamos que el hardware y el software no se habían creado en función exclusiva del periodismo sino, más bien, en función de un innominado socialware. 


\section{DÉFICIT DE LA IMAGINACIÓN TECNOECONÓMICA}

El déficit de imaginación tecnoeconómica en el artículo de 2000 obedece a que mi primera reflexión fue históricamente "seguidista": si la prensa modélica había sobrevivido a la radio y a la televisión, también podría coexistir con las NTS y, específicamente, con Internet. Para esto bastaba incorporar dichas NTS al proceso de pre-impresión o incorporarse ella misma a Internet, según conveniencias mutuas. Así, los diarios-papel disfrutarían del público ampliado on line e Internet enriquecería sus contenidos tomando, como referente expreso, a los grandes y confiables diarios-papel. El desafío parecía abordable. Todos ganaban.

No hubo, entonces, un análisis cabal de las rigideces económicosociales de la reconversión de la prensa. Por ejemplo, no se ponderaron los serios problemas que planteaba la inversión en maquinarias y equipos de larga duración en contraste con la inversión en sistemas de rapidísima obsolescencia. Tampoco se ponderó la resistencia sindical al desempleo, que acompaña siempre a las actualizaciones tecnológicas importantes. Más allá, no se abordó el tema de la desventaja comparativa total del soporte papel, en función de su costo y de la energía disponible para producirlo. Algo debió decirse sobre un hecho significativo: producir una tonelada de papel consume una energía equivalente a 6 barriles de petróleo; producir una tonelada de acero consume una energía equivalente a 5 barriles y fracción.

En ese contexto, los problemas financieros habían puesto al periodismo tradicional ante una de sus más serias crisis recurrentes. Para superarla, apelaba a medidas que hoy parecen intermedias o propias de periodos "normales". Entre esas medidas estaban redefinir sus contenidos dando menos política, aumentando las dosis de farándula y fútbol, "purificando" los textos de toda palabra culta, reduciendo el tiempo óptimo calculado de lectura, incorporando secciones o suplementos según dispusieran las encuestas, absorbiendo las revistas -semanales o quincenales- en el cuerpo de los diarios y 
absolutizando la conversión al color. De hecho, el viejo periodismo estaba en un momento de inflexión.

También estaba la ilusión de los mayores recursos (o menores pérdidas) vía racionalización interna. Esto comprendía la reconversión de los propios periodistas, que ya no se dedicarían sólo a cazar noticias y componer textos. Además, tendrían que dimensionar, diagramar y mover sus trabajos desde sus computadores satelitales, según programas o softwares especiales. En esa misma línea, se privilegiaba la venta de suscripciones por sobre la venta del periódico en puntos fijos o móviles de distribución. Otro punto era el énfasis absoluto en la publicidad, que transformó al diario de los domingos en un catálogo de avisos comerciales con un suplemento de noticias. Por último, ahí estaba, como siempre, la concentración o absorción de los medios por los grandes consorcios, dejando cada vez menos espacio a la prensa independiente, nacional o local.

Tecnológicamente hablando, aquello era demasiado poco y demasiado tarde. La opción del futuro no era modernizarse hasta la etapa de preimpresión, sino programar el abandono del soporte papel, para internetizarse. La mejor prueba está en la rendición progresiva y disfrazada de la prensa modélica. Esta ahora contiene blogs, chats, videos y twitteos en sus páginas-papel y también suele tener una versión on line, con o sin pago de los internautas. El fenómeno refleja ese dicho sajón según el cual if you can't beat them, join them. Pero también puede contener la ilusión de utilizar transitoriamente las NTS, esperando el retorno a los viejos buenos tiempos. Algo similar a lo que hacían los grandes cineastas de antaño, cuando producían filmes "alimenticios" para financiar sus genuinas obras de arte.

Sin embargo, no parece viable vivir apostando al caballo ajeno, en cuanto ganador, para poder mantener el propio. La prensa-papel, en estos momentos, podría terminar compitiendo con sus propias versiones on line y, si estas son pagadas, chocaría con la gratuidad de la información que nace desde Internet. Todo esto ha dejado espacio para un efecto curioso: el desarrollo de los diarios-papel de distribución gratuita, que se financian sólo con publicidad. Hay en todo 
esto una paradoja inadvertida: la información que se asume con un diario-papel que se regala o con un simple clic en una dirección web está resocializando la práctica ancestral de la información gratuita, esa de los tiempos en que a nadie se le hubiera ocurrido pagarle a los heraldos del rey.

Un buen ejemplo de lo anterior se produjo en Chile cuando los responsables del casi centenario diario La Nación-subvencionado, en cuanto mayoritariamente estatal-, asumieron por fin su crisis total de compradores. En diciembre de 2010 terminaron con la edición papel y optaron por potenciar su versión digital. A tres meses de la decisión, en marzo de 2011, el diario tenía 900 mil visitas mensuales, con una proyección de crecimiento a 2 millones de lectores sólo en el corto plazo. Con base en fenómenos como este ya existe en el mundo una bolsa virtual de medios, en la cual se transan los tradicionales y los digitales. Grandes medios on line como el Huffington Post se han ultravalorizado, y medios tan históricos como The New York Times han iniciado una marcha forzada hacia la internetización.

\section{DÉFICIT DE LA IMAGINACIÓN POLÍTICA}

El déficit de imaginación política de 2000 impidió visualizar que el realismo minimalista era y es funcional a la identificación de los políticos como clase profesional. Desde ese realismo no se aprecia y hasta se niega su calidad, pero se asume que son mejores que nada, pues "alguien tiene que gobernar". Este fenómeno completó su maduración con la crisis de las "ideologías totales" tras el fin de la Guerra Fría y con la consiguiente centrificación de los actores sistémicos. En efecto, ante aquel vacío repentino casi todos se abalanzaron hacia el centro de sus sistemas respectivos, abriéndose a una profesionalización sin creatividad. En ese nuevo contexto la imaginación se hizo sospechosa y comenzó a sustituirse el debate de ideas por las acciones mercadotécnicas. En vez de proyectos de sociedad, los candidatos ofrecían sus rostros y hasta eludían las filiaciones partidistas. El viejo pragmatismo dejó de ser, entonces, un 
factor dirimente del debate político para convertirse en una especie de doctrina de lo políticamente correcto. Un primer diagnóstico diría que el fin de los sueños ideológico-escatológicos llegó a confundirse con el fin de todos los sueños, y que el mercado, en vez de eficiente asignador de recursos, tendió a confundirse con la sociedad de mercado. Lester Thurow, notable teórico del extremomercadismo, expuso en su libro El Futuro del Capitalismo el espíritu descarnado de esta etapa: "en el capitalismo simplemente no existe un deber ser social [...] la democracia tiene creencias que no son compatibles con las grandes desigualdades".

De lo señalado derivan tres efectos colaterales, no previstos pero que debieron preverse:

- Primero, la legitimación de las dictaduras y teocracias vigentes, y con mayor convicción si estas ofrecían buenos negocios o mercados apetecibles. Podría hablarse, en este sentido, de la amistad fructífera de los gobernantes del realminimalismo democrático con Hosni Mubarak, Muamar el Gadafi, reyes, jeques y emires petroleros. También podría hablarse de su tolerante indiferencia hacia actores dictatoriales o teocráticos económicamente irrelevantes, como los hermanos Castro, los hermanos Ortega y muchos gobernantes africanos.

- Segundo, la necesidad del enemigo y amigo sustitutos. Según este efecto, el fundamentalismo islámico ocuparía el espacio de la religión soviética derrotada y algunos dictadores "progresistas" serían los nuevos amigos de los huérfanos de la u.R.S.s. Por eso, para combatir a Sadam Hussein, George W. Bush debió disfrazarlo de Bin Laden, mientras Hugo Chávez y los hermanos Castro confraternizaban con Gadafi, en cuanto actor vinculado a la Internacional Socialista. En parte, esto era una reproducción de la dicotomía totalitarismos repudiables/autoritarismos conversables, elaborada durante la Guerra Fría por la politóloga norteamericana Jeanne Kirkpatrick para justificar la buena relación de los Estados Unidos con algunos dictadores oprobiosos. Lo mismo había dicho antes Lyndon B. Johnson, 
aunque sin eufemismos, cuando aludió al dictador nicaragüense Anastasio Somoza como "our son of a bitch".

- Tercero, la paulatina mutación de muchos partidos políticos en simples gestores del poder. En distintos grados de nitidez, tal conversión los mostraba como cajas retóricas de resonancia, con un plantel de operadores expertos en sistemas y métodos clientelares, que abrían las puertas de la corrupción sistémica. Había en esto una complicidad estructural con algunos medios de prensa, con anclaje en la publicidad imprescindible, que se expresaba como afonía crítica. Esos medios, para evitar colisiones con los intereses políticos de sus avisadores, cerraban así un circuito desventurado y los dictadores dejaban de ser noticia internacional preferente.

\section{DÉFICIT DE IMAGINACIÓN PROSPECTIVA EN LO GENERACIONAL}

Mi hipótesis es que los jóvenes con vocación política de hoy primero se sintieron excluidos por los partidos políticos y después ya no quisieron incluirse. Agrego que todavía no descubren una buena razón para "volver" a un sistema democrático al que nunca entraron. Por lo mismo, tampoco los motiva sostener a la prensa que se producía en ese sistema y que ayudaba a reproducirlo. Recuerdo a un distinguido parlamentario de la Concertación chilena, entonces gobernante, reconociendo que no había jóvenes en su partido, pero matizando luego: "los pocos que tenemos están, porque son iguales a nosotros".

Hubo demasiada autocomplacencia ante este fenómeno. Se quiso creer que quienes no se interesaban por participar en el sistema político estaban conformes con este, es decir, los desencantados o abstinentes, entre los cuales está la abrumadora mayoría de los jóvenes, eran una suerte de satisfechos subliminales. No se quiso sospechar que esa apatía constituía una etapa de transición, que podía conducir a la viejísima opción entre reforma o revolución. 
Hay dos conexiones que no se hicieron: la primera, que la deserción política de los jóvenes fue simétrica con su desvinculación de la gran prensa. Si ellos compraban periódicos era para buscar ofertas de empleo. Segunda conexión ausente: tanto esa deserción como esta desvinculación fueron coetáneas con la invención y auge de las NTs, porque fueron los jóvenes quienes las inventaron y quienes las están aplicando. Bill Gates creó Microsoft a los 20 años cuando era estudiante de Harvard. Mark Zuckerberg y su pandilla veinteañera de Harvard crearon Facebook, que hoy tiene 500 millones de afiliados (según cifra de inicios de 2011). Tan cierto es esto que yo debí recurrir a mi hija para aprender a enviar mensajes por celular y dependo de mi nieta para que me reprograme el aparato. Supongo que no soy el único adulto en estas condiciones de dependencia.

Lo señalado tampoco anuncia un paraíso con administración juvenil. Ya advertimos en 2000 que Internet no está estructurado como un proyecto periodístico. Es un sistema abierto, sin director responsable, sin director de informaciones, donde se mezclan lo óptimo, lo pésimo, lo santo, lo perverso, la desinformación, la falsificación, la pornografía y la propaganda de las dictaduras, todo al alcance de una tecla. Por lo mismo, las NTs también pueden ser funcionales al progreso tecnológico de la delincuencia común. Una entrevista del diario brasileño O'Globo del 23 de mayo de 2007 a Marcos Camacho, alias Marcola, delincuente líder de São Paulo, es muy reveladora a este respecto. En ella se indica que "no hay más proletarios o infelices o explotados, hay una tercera cosa creciendo allá afuera, cultivada en el barro, educándose en el más absoluto analfabetismo, diplomándose en las cárceles [...] ya surgió un nuevo lenguaje. Es otra lengua. La post miseria genera una nueva cultura asesina ayudada por la nueva tecnología, satélites, celulares, armas modernas. Es la mierda con chips, con megabytes". 


\section{NUEVA FORMA DE PENSAR, SOCIALIZAR Y COMUNICAR}

A inicios de este milenio veíamos a los jóvenes internautas como simples nerds - una nueva clase de "mateos" o empollones-, mientras ellos estaban diseñando una socialización de nuevo tipo, con soporte en las NTS. Con ese objetivo primero crearon redes sociales; luego las fijaron -con blogs, facebook, twitter, youtube, mensajes de texto y skype-, y terminaron creando un paralenguaje oral, escrito e icónico, que hoy es la lengua materna juvenil. Tal vez sin saberlo estaban iniciando la cuarta fase en la Historia de la Comunicación Social tras las de la oralidad, escritura y audiovisualidad: la era de la comunicación on line (col).

La Col es ese lenguaje tan presentido por escritores como Julio Cortázar, George Orwell, Aldous Huxley y Anthony Burgess. En su superficie se caracteriza por la desmaterialización de la palabra escrita que, al abandonar su tablado de papel, inspira una permisividad insólita. Sus usuarios pueden fragmentarla, ajustarla, colectivizarla, intervenirla y expropiarla, aboliendo cualquier copyright. No hay contexto tradicional que pueda impedírselos. En el sustrato del fenómeno está una característica imponente: la rapidez de su producción. En efecto, la col es una genuina novedad civilizacional, en cuya virtud la información se procesa en tiempo real, sintetizando los clásicos tres tiempos de la prensa-papel: el tiempo del acontecimiento, el tiempo del procesamiento periodístico y el tiempo de la distribución.

Sabemos, desde Marshall Mc Luhan, que los medios no son sólo rutas de información, pues, simultáneamente, modelan el pensamiento. La COL, en cuanto nuevo lenguaje producido por las NTs, lo confirma en vivo y en directo, pues contiene un nuevo enfoque gnoseológico que produce una nueva manera de pensar, de crear cultura y de posicionarse políticamente. En esta línea, el nuevo posicionamiento político genera, por lo menos, tres opciones decisivas: la primera, el mejor político es el que menos político parece; la segunda, en vez de 
optar por sistemas políticos establecidos, los jóvenes prefieren crear una politicidad propia; y la tercera, donde esta politicidad implica usar el sistema de socialización e información que hemos denominado socialware. Lo decisivo en este proceso, por el momento, es que la politicidad propia se inscribe en la tradición democrática y, por tanto, es disfuncional a quienes no asumieron, en los sistemas políticos y mediáticos, que la democracia y las libertades fundamentales son y deben ser para todos.

Vaya una digresión importante sobre este punto: muchos intelectuales de primer nivel miran el fenómeno col con aprensión sectorializada. Paradigmático es lo expresado por Mario Vargas Llosa, último Premio Nobel de Literatura e influyente líder de opinión a nivel global. A su juicio es preocupante que, mediante las NTs, los jóvenes acorten las palabras y vulneren las reglas gramaticales en los chats de Internet o en Twitter y Facebook. Esto implicaría que Internet "ha liquidado la gramática" y que "si escribes así, es que hablas así; si hablas así, es que piensas así y si piensas así, es que piensas como un mono"3. Por cierto, es la perspectiva de un maestro del lenguaje -por extensión, de los intelectuales vinculados a las bellas letras-, que contrasta la cultura emergente con la que creen estar custodiando (y reproduciendo). Para la mayoría de estos intelectuales la col es sólo un lenguaje empobrecido como cualquier jerga local de cualquiera época. Otros más apocalípticos creen que es síntoma de la crisis inexorable de la Cultura -con mayúscula y en singular- a la cual miran como un segmento terrenal del plan divino o un producto social acabado. En tal condición, la cultura debiera moverse de manera rectilínea y eventualmente ascendente, como si fuera el acoplado de una Historia que nos arrastra hacia un fin. Sin embargo, las culturas realmente existentes siempre han estado insertas en la historia multívoca, expuestas a quiebres, paralizaciones y retrocesos, desde la barbarie, al Renacimiento y de este a la Segunda Guerra Mundial. Es lo que expresa el elocuente aserto-pregunta de Raymond Aron en una de sus obras más célebres: "Cada momento

3 Entrevista en semanario uruguayo Búsqueda, versión de diario chileno El Mercurio, 29 de abril de 2011. 
de la historia tiene varios sentidos, ¿puede la historia entera tener sólo uno?". El hecho es que McLuhan en los años 60 ya pensaba en ese tipo de objeciones a los nuevos comunicadores, cuando pergeñó su estupendo aforismo "nadie ha cometido jamás un error gramatical en una sociedad analfabeta" 5 .

\section{LOS NUEVOS POLÍTICOS}

El nuevo posicionamiento y la nueva politicidad son un gran subtema en proceso. A nuestra vista está la insurgencia en Egipto, el Magreb y otros países árabes, con una repercusión global equivalente a "la caída de los muros" de 1989. En Europa y los Estados Unidos siguen manifestándose "los indignados" y en Chile, cómo no, tenemos los marchosos estudiantes de 2011. Por algo The Economist decodificó los sucesos árabes como una suerte de admonición, dirigida a quienes sostenían que en esos países no estaban preparados para mejorar su estatus sociopolítico y que sus dictadores eran la única defensa contra el fundamentalismo islámico: "A los estudiantes testarudos de la realpolitik les gusta pensar que sólo ellos ven el mundo como es realmente y que aquellos que persiguen los derechos humanos y la democracia tienen la cabeza en las nubes" ${ }^{\text {. }}$ Por lo mismo, otros medios exhumaron la palabra "revolución", que tanto prestigio tuvo durante los años de la Guerra Fría. Sin embargo, a diferencia de las antiguas, en la revolución árabe no se percibió una doctrina política previa. Como habría dicho Machado, "se conceptualizó al andar" sobre una base minimalista pero poderosa: realizar la democracia y las libertades, prometidas pero congeladas.

¿Se trata, entonces, de una revolución retórica, sin el aporte de la fuerza? No lo creo. Aunque con menos visibilidad que en el asalto bolchevique al Palacio de Invierno, los insurgentes actuales han sido fieles a ese aporte de Marx, según el cual "las armas de la crítica

\footnotetext{
$4 \quad$ Aron, Raymond, El opio de los intelectuales, Ediciones Siglo Veinte, Buenos Aires, p. 161.

5 Aron, Raymond, La Galaxia Gutenberg, Editorial Planeta-De Agostini, Barcelona, 1985, p. 282.

6 Versión en castellano de El Mercurio, 25 de febrero de 2011.
} 
preceden a la crítica de las armas". La diferencia epocal radica en que las armas de la crítica se ejercieron sin antes mostrarse y la crítica de la fuerza llegó sin que se programara. Dicho de otra manera, aquí no vimos la etapización histórica "normal": construcción del partido revolucionario, creación de su aparato de "agitprop", política de alianzas funcional a la idea revolucionaria, acopio de arsenales para disuadir o actuar y convocatoria a la sociedad nacional. En esta "revolución árabe" (en proceso), quienes manipulaban las NTS plantearon el objetivo revolucionario y forjaron la fuerza en tiempo real, comprometiendo incluso a la fuerza establecida. De paso, exhibieron una enorme superioridad sobre esa prensa papel tan fácilmente bloqueable, sobre todo al interior de los cuarteles. El equivalente a la toma del Palacio de Invierno no tuvo una Iskra preparatoria y fue, en definitiva, la toma de los centros de Internet.

La otra gran pregunta que formulan las almas prácticas es: ¿dónde están los nuevos líderes políticos? Por supuesto es la gran incógnita del presente. Desde nuestra cultura política sólo podemos asegurar que los habitantes de la web no plantean ni presentan candidaturas tradicionales y que, técnicamente, estas son disfuncionales a los 140 caracteres que exige el twitteo. Además, el predicamento de algunos barones de la col es que los líderes políticos ni siquiera son necesarios: "Lo que ustedes no entienden, y parece ser que no lo quieren entender, es que esta protesta no tiene organizadores reales [...] es una protesta sin un líder", dijo Wael Ghonim, ejecutivo de Google para el Medio Oriente y norte de África, a propósito de Egipto?.

Aunque Ghonim quizás no lo sepa, la prescindibilidad de los líderes políticos entronca con una notoria subutopía marxista, esa según la cual la sociedad futura no necesitaría el gobierno sobre las personas, pues le bastaría la administración sobre las cosas. Lo que está sucediendo de facto es que los líderes de la nueva politicidad están madurando en la propia web. Allí están y pronto emergerán. Baste pensar que la bloguera cubana Yoani Sánchez, sometida a todo tipo de censuras internas, tiene una base de apoyo propia de más de 100

$7 \quad$ Newsweek, 16 de febrero de 2011. 
mil seguidores en su cuenta de twitter. Comparativamente el sitio en el cual se publican las reflexiones de Fidel Castro tiene 20.750 seguidores, según reciente medición de Aol. A mayor abundancia, mientras se escriben estas líneas apareció la lista de las 100 personas más influyentes del mundo, según la revista Time. En esa lista están personalidades de las NTs como Julian Assange y Reed Hastings - presidente de una empresa de video por Internet- y la encabeza Wael Ghonim. En Chile está el caso notorio de Camila Vallejo, que saltó desde las marchas estudiantiles a un cuarto lugar entre los políticos con más futuro, ahorrándose la marcha por las instituciones.

El poder de las NTS equivale al del "arma total" durante la Guerra Fría y plantea un dilema insoluble al poder establecido. Por la alta velocidad de la información que diseminan y por la masividad global de los informados, su control previo es prácticamente imposible. Cortar Internet de manera global, como medida de censura previa, equivaldría a un disparo a los pies propios. A semejanza de la utópica huelga general revolucionaria del viejo comunismo, afectaría masivamente la actividad económica del país, pero no por obra de los insurgentes, sino del propio gobierno. Y todo esto sin contar con que habrá wikileaks cuándo y dónde menos se piense.

La col puede burlar la censura gracias a la autocontención obligada del poder establecido y también gracias a contramedidas tecnológicas como los servidores externos pivotales y la triangulación de mensajes y twitteos. Todo esto se ha testeado en el proceso de la "revolución árabe". Podemos recordar que el diario argentino Clarín, del 2 de febrero de 2011, informó desde El Cairo que "la censura en la web intentó frenar la revuelta, pero causó un caos económico”. Otro ejemplo está en la información del $1^{\circ}$ de marzo de 2011, desde Bengasi, de la cadena árabe de televisión Al Jazeera. Esta mostró lo siguiente: "en el principal edificio de justicia se organizan las principales acciones para derrocar a Gadafi [...] en su interior hay un centro de Internet donde un pequeño equipo de técnicos trabaja en sus laptops". Para Al Jazeera, era una "revolución cibernética" en la cual esos técnicos arreglaron el sistema tras un apagón total de Internet, se comunicaban con las cadenas CNN y BBC mediante Skype y chats, 
trabajaban en Facebook y Twitter y tenían una impresora de oficina para producir carteles y banderas.

De paso, todo esto compone un excelente aporte para quien se dedique a investigar la actualidad y obsolescencia de la clásica obra de Curzio Malaparte, Técnica del golpe de Estado.

\section{DIEZ CONCLUSIONES RECTIFICATORIAS}

A continuación, algunas conclusiones de lo expuesto:

- Primera: hoy no está en peligro el periodismo mismo o esencial, sino el tradicional y modélico con soporte en papel. Según los datos y tendencias actuales, será desplazado de su importancia histórica por el periodismo con soporte electrónico de las NTS.

- Segunda: para el periodismo emergente, la globalización comprende el proyecto democrático o no es globalización. Es un avance sobre el realismo minimalista del periodismo tradicional, que se venía resignando a los statu quo no democráticos en función de la estatura socioeconómica de las naciones afectadas y/o de sus intereses empresariales propios.

- Tercera: hay un lenguaje comunicacional nuevo que genera nuevas maneras de pensar, comunicarse y actuar. Estas nuevas maneras generan, a su vez, una nueva politicidad, caracterizable por ser un atajo directo (shortcut en lenguaje computacional) entre la información, la convocatoria y la acción.

- Cuarta: las NTS, con base en la comunicación on line, tienen un soporte generacional definido, pues nacieron y se expandieron con la juventud tecnotrónica. Por esto, decirle a los jóvenes que busquen su información en la prensa seria es como pedirles que renuncien a sus ventajas comparativas genuinas. Es como 
si ellos nos conminaran a leer nuestros periódicos en castellano antiguo.

- Quinta: el binomio prensa tradicional sin filo crítico y apatía política ciudadana no era un fenómeno estático, sino una etapa de un periodo de transición. Este se produce desde aquella politicidad resignada a la participación mínima y se dirige hacia la politicidad de las mayorías excluidas, con soporte en las NTS.

- Sexta: las redes sociales de las NTs no reemplazan a la participación política. Son una nueva forma de participación política, en cuyo contexto pueden crearse nuevos centros convocantes, con objetivos temáticos acotados, que produzcan líderes legitimados por los resultados.

- Séptimo: para los jefes de los partidos políticos ya no se trata de ser más inclusivos, especialmente con los jóvenes, pues los marginales a los partidos tienen hoy la misma o mejor información y mayor capacidad de convocatoria. Las opciones reales del momento son negociar con ellos o unirse a ellos, ya que es más posible que los excluidos modifiquen a los partidos que el fenómeno inverso.

- Octava: lo que está sucediendo puede ser el comienzo del fin del conformismo con las democracias de baja o nula intensidad, es decir, con el conformismo de los partidos políticos clientelares, compuestos por dirigentes vitalicios, militantes teloneros y masas manipulables. Frente a ellos, los internautas se autoperciben como participantes democráticos ab initio, con influencia sobre una masa crítica y en crecimiento exponencial.

- Novena: la validez de lo sostenido se está verificando en el propio establishment político, con los militantes que asumen la nueva politicidad, socavando las disciplinas partidarias -"díscolos" y "trásfugas"- y los que están aprendiendo el oficio de blogueros y twitteros. Es lo que ha contribuido a instalar en el debate político temas transversales a los partidos, como la 
protección de los ecosistemas, la implantación de la huella de carbono, el cambio climático, la protección de las especies en extinción, el problema del agua y el combate a todas las dictaduras.

- Décima: como lo muestra la "revolución árabe", la crisis de los partidos políticos ha dejado de identificarse, automáticamente, con la crisis de la idea democrática. Ahora, puede gatillarse una gestión democrática sobre otras bases, según la crisis sea coyuntural o terminal. Aunque todavía no se perciba así, esto implica que la representación política sin participación democrática genuina ya no tiene como única alternativa la implantación de una dictadura.

\section{DOS CONCLUSIONES PERSONALIZADAS}

Primera: pronto nadie sabrá qué cosa era un suplementero o un quiosco de periódicos, pero nosotros seguiremos comprando diarios en boutiques especiales, pues el mercado nos considerará en la categoría "coleccionistas". Esto significa que la prensa con soporte papel seguirá la ruta de los innecesarios sellos postales y que algunos literatos ironizarán sobre cuanto disfrutábamos los antiguos con su olor a tinta fresca.

Segunda: puede que mis pronósticos de hoy tampoco sean certeros y que mañana piense que incurrí en un exceso de la imaginación prospectiva. En tal caso, lo peor que puede suceder es que ello de pábulo para un tercer artículo sobre el futuro del periodismo, en los diez años que vendrán. 
